\title{
Clinical signs in the Wernicke-Korsakoff complex: a retrospective analysis of 131 cases diagnosed at necropsy
}

\author{
CG HARPER, M GILES, R FINLAY-JONES
}

From the Department of Neuropathology, Royal Perth Hospital, Psychiatric Services, Health Department of Western Australia, Australia

SUMMARY A recent necropsy study has shown that $80 \%$ of patients with the Wernicke-Korsakoff syndrome were not diagnosed as such during life. Review of the clinical signs of these cases revealed that only $16 \%$ had the classical clinical triad and $19 \%$ had no documented clinical signs. The incidence of clinical signs in this and other retrospective pathological studies is very different from that of prospective clinical studies. This discrepancy may relate to "missed" clinical signs but the magnitude of the difference suggests that at least some cases of the Wernicke-Korsakoff syndrome may be the end result of repeated subclinical episodes of vitamin B1 deficiency. In order to make the diagnosis, clinicians must maintain a high index of suspicion in the "at risk" group of patients, particularly alcoholics. Investigations of thiamine status may be helpful and if the diagnosis is suspected, parenteral thiamine should be given.

Wernicke's encephalopathy is an easily treated but potentially fatal disease due to thiamine deficiency. In western society it occurs predominantly in alcoholics, ${ }^{1}$ although it can occur in malnutrition from any cause. Wernicke considered the typical clinical features to comprise ophthalmoplegia, gait ataxia and an abnormal mental state. ${ }^{2}$ Victor and his colleagues mentioned nystagmus as an important occular sign. ${ }^{3}$ They commented that more than $90 \%$ of affected patients manifest mental symptoms which can range from a mild delerium to a global confusion. ${ }^{3}$ From a pathological point of view the histological findings and in particular the periventricular distribution of the lesions are usually considered to be specific enough as to be diagnostic.

Korsakoff's psychosis is characterised by profound amnesia, disorientation and often confabulation. It seems to have the same pathological substrate as Wernicke's encephalopathy and probably represents a variation in the clinical manifestations of the same disorder. Many authors in fact talk of the WernickeKorsakoff syndrome. ${ }^{3}$ We will refer to these three en-

Address for reprint requests: Dr C Harper, Department of Neuropathology, Royal Perth Hospital, Wellington Street, Perth, WA 6000 , Australia.

Received 19 July 1985. Accepted 1 September 1985 tities as the Wernicke-Korsakoff complex for the remainder of this paper.

The classical clinical triad of symptoms as described by Wernicke ${ }^{2}$ persists in the literature and in the minds of many of the medical profession despite the fact that several authors have emphasised that it is by no means the inevitable clinical picture. ${ }^{13-5}$ However, it appears that the clinical diagnosis is still being missed and this is emphasised by a recent necropsy study of 131 cases of the Wernicke-Korsakoff complex. ${ }^{1}$ The clinical diagnosis of either Wernicke's encephalopathy, Korsakoff's psychosis or the Wernicke-Korsakoff syndrome had been made in only $20 \%$ of the 131 cases despite the fact that almost three quarters of the patients had been seen in a major hospital during the latter part of their life. ${ }^{1}$ This finding raises several important questions. Firstly are the traditional diagnostic criteria for the WernickeKorsakoff complex too rigid and secondly could there be a subclinical form of Wernicke's encephalopathy which, following repeated episodes, could give rise to the pathological damage typical of the WernickeKorsakoff complex? ${ }^{13}$ Finally, is there a difference between the clinically defined conditions of the Wernicke-Korsakoff complex and the pathologically defined entity? In an attempt to address these questions the authors have reviewed and analysed the clinical data on the 131 cases of the Wernicke-Korsakoff 




Fig Diagrammatic representation of the incidence of clinical signs in the 97 cases of the Wernicke-Korsakoff complex.

complex which were diagnosed at necropsy. ${ }^{1}$

\section{Materials and methods}

Clinical data for each case were sought from the major hospitals in Perth, from the Perth City Coroner's Department, from the Mental Health Services and from the Hospital Morbidity Data Services for Western Australia. Sixty four patients had died in one of the major Perth hospitals and hospital case notes were found on an additional 33 cases. Thus there was good clinical documentation on 97 of the 131 cases, and these 97 cases form the basis of this report.

Data collection included the name, age and sex of each patient, details of hospital admissions including diagnoses in ward notes and discharge summaries and a history of alcoholism and/or malnutrition. Hospital notes were scanned for documentation of abnormalities of eye movements, gait and mental state (including level of consciousness, memory, disorientation, etc). Investigations concerning vitamin status and treatment with vitamin supplements were also noted.

Necropsy was performed on each case so that detailed information was available concerning cause of death, presence of liver disease and abnormalities in the brain.

Because of the diverse terminology used in the hospital records for each patient, clinical signs were subdivided into:- (1) Eye signs: nystagmus and/or ophthalmoplegia, (2) Ataxia-ataxia, "can't walk", (3) Mental signsdisorientation, confusion, coma, drowsiness, poor memory and confabulation.

\section{Results}

Ninety-four of the 97 patients were chronic alcoholics. Of the other three cases one patient had had a small bowel resection four weeks prior to his death and one had had a previous subtotal gastrectomy.

Only 33 of the 97 cases were diagnosed as either Wernicke's encephalopathy, Korsakoff's psychosis or the Wernicke-Korsakoff syndrome during life. The figure and table 1 detail the incidence of eye signs, ataxia and mental signs in the 33 "diagnosed" and 64 "undiagnosed" cases. Sixteen percent of the 97 cases had all three clinical signs (the classical triad), $28 \%$ had two signs, $37 \%$ had only one clinical sign and in $19 \%$ of the cases there were no clinical signs documented. Of the "undiagnosed" cases 20 had died at home and 44 had died in hospital; seven of this latter group were comatose prior to death. No other clinical signs of the Wernicke-Korsakoff complex were documented in the coma group.

As might be anticipated, the classical triad of clinical signs was three times more common in the "diagnosed" group compared to the "undiagnosed" group. A disturbing feature is the fact that four patients had the classical triad of clinical signs of the WernickeKorsakoff complex documented in their hospital records but they were not diagnosed or treated.

With regard to the percentage of cases with either one or two clinical signs of the Wernicke-Korsakoff complex the "diagnosed" and "undiagnosed" groups were almost identical (table 1). Cases in which no clinical signs of the Wernicke-Korsakoff complex were documented were far more common in the "undiagnosed" group (27\%) compared to the "diagnosed" group (3\%). No specific tell-tale pattèrns of clinical signs were recognised in the two groups of cases, the incidence of mental, ataxia and eye signs being very similar.

Of the 33 "diagnosed" cases, six had died at home

Table 1 Incidence of clinical signs in 97 cases of the Wernicke-Korsakoff complex

\begin{tabular}{|c|c|c|c|c|}
\hline \multicolumn{2}{|c|}{ Clinical signs } & \multirow{2}{*}{$\begin{array}{l}\text { Undiagnosed cases } \\
n=64 \\
4(6 \%) \\
12(19 \%) \\
5(8 \%) \\
1(1 \cdot 5 \%) \\
1(1 \cdot 5 \%) \\
2(3 \%) \\
22(34 \%) \\
17(27 \%)\end{array}$} & \multirow{2}{*}{$\begin{array}{l}\text { Diagnosed cases } \\
n=33 \\
12(37 \%) \\
5(15 \%) \\
3(9 \%) \\
1(3 \%) \\
0(0 \%) \\
0(0 \%) \\
11(33 \%) \\
1(3 \%)\end{array}$} & \multirow{2}{*}{$\begin{array}{l}\text { Total } \\
n=97\end{array}$} \\
\hline $\begin{array}{l}\text { Three: } \\
\text { Two: } \\
\text { One: } \\
\text { None: }\end{array}$ & $\begin{array}{l}\text { Classical triad } \\
\text { Ataxia/Mental } \\
\text { Mental/Eye } \\
\text { Eye/Ataxia } \\
\text { Ataxia } \\
\text { Eye } \\
\text { Mental }\end{array}$ & & & \\
\hline
\end{tabular}


Table 2 Clinical signs of the Wernicke-Korsakoff complex in 33 "diagnosed" cases

\begin{tabular}{|c|c|c|c|c|c|}
\hline \multicolumn{2}{|c|}{ Clinical signs } & \multirow{2}{*}{$\begin{array}{l}\text { Died at } \\
\text { home } \\
n=6\end{array}$} & \multirow{2}{*}{$\begin{array}{l}\text { Died hospital } \\
\text { diagnosis } K P \\
n=12 \\
0\end{array}$} & \multirow{2}{*}{$\begin{array}{l}\text { Died hospital } \\
\text { diagnosis } W E \\
n=5 \\
4\end{array}$} & \multirow{2}{*}{$\begin{array}{l}\text { Died hospital } \\
\text { diagnosis } W-K \\
n=10 \\
6\end{array}$} \\
\hline Three: & Classical triad & & & & \\
\hline Two: & Ataxia/Mental & 0 & 4 & 0 & 1 \\
\hline & Mental/Eye & 1 & 0 & 1 & 1 \\
\hline & Eye/Ataxia & 1 & 0 & 0 & 0 \\
\hline \multirow[t]{2}{*}{ One: } & Ataxia & 0 & 0 & 0 & 0 \\
\hline & Mental & 1 & 8 & 0 & 2 \\
\hline None: & & $i$ & 0 & 0 & 0 \\
\hline
\end{tabular}

KP $=$ Korsakoff's psychosis

$\mathrm{WE}=$ Wernicke's encephalopathy

$\mathrm{W}-\mathrm{K}=$ Wernicke-Korsakoff syndrome

and the remainder in hospital. Those who died in hospital had a range of diagnoses: Wernicke's encephalopathy ( 5 cases), Wernicke-Korsakoff syndrome (10 cases) and Korsakoff's psychosis (12 cases). The incidence of clinical signs for each of these groups is shown in table 2 . The majority of cases diagnosed as Wernicke's encephalopathy or the WernickeKorsakoff syndrome had the classical clinical triad whereas two thirds of the cases diagnosed as Korsakoff's psychosis exhibited mental changes only.

The single most common clinical observations for the 97 cases was disorientation $(42 \%)$, followed by ataxia or difficulty in walking $(37 \%)$ and poor memory $(30 \%)$. Seventy six percent of the cases exhibited nystagmus and/or ophthalmoplegia in the "diagnosed" and "undiagnosed" groups is shown in table 3. The combined eye signs of nystagmus plus ophthalmoplegia were far more common in the "diagnosed" group (33\%). The absence of eye signs was more common in the "undiagnosed" group (81\%). Ataxia was noted in $37 \%$ of the cases.

Of the 18 patients who had no documented signs of the Wernicke-Korsakoff complex, 16 had been seen in major hospital casualty departments, at fracture clinics and the like. One patient had died of a stroke soon after admission and one patient had not had an examination of the central nervous system during a five week admission for pneumonia.

Each case was classified as acute, acute on chronic (acute/chronic) or chronic Wernicke's encephalopathy based upon standard and well accepted histopathological criteria. ${ }^{13}$ Table 4 summarises the pathological stage of the disease in relationship to the "diagnosed" and "undiagnosed" groups. There is surprisingly little difference in the incidence of the acute plus the acute/chronic forms of the disease in the "diagnosed" (39\%) and "undiagnosed" (34\%) groups. Of the seven patients who died in coma (undiagnosed), three had acute or acute/chronic Wernicke's encephalopathy. Although the acute form of Wernicke's encephalopathy is a well recognised cause of coma and/or sudden death ${ }^{6}$ there is no good evidence to suggest that chronic lesions of Wernicke's encephalopathy cause either coma or sudden death.

The clinical diagnoses of the 64 "undiagnosed" cases ranged from dilantin toxicity to schizophrenia but the most common diagnoses were "dementia" (13) and "liver failure" (9). In consideration of the outcome of cases in which the diagnosis of the Wernicke-Korsakoff complex had been missed there

Table 3 Incidence of eye signs in 97 cases of the Wernicke-Korsakoff complex

\begin{tabular}{lccc}
\hline Eye signs & $\begin{array}{l}\text { Undiagnosed cases } \\
n=64\end{array}$ & $\begin{array}{l}\text { Diagnosed cases } \\
n=33\end{array}$ & $\begin{array}{l}\text { Total } \\
n=97\end{array}$ \\
\hline Nystagmus & $6(9 \%)$ & $4(12 \%)$ & $10(10 \%)$ \\
Ophthalmoplegia & $3(5 \%)$ & $1(3 \%)$ & $4(4 \%)$ \\
Nystagmus \& Ophthalmoplegia & $3(5 \%)$ & $11(33 \%)$ & $14(15 \%)$ \\
None & $52(81 \%)$ & $17(52 \%)$ & $69(71 \%)$ \\
\hline
\end{tabular}

Table 4 Pathological stage of Wernicke-Korsakoff complex

\begin{tabular}{llcl}
\hline $\begin{array}{l}\text { Histological stage } \\
\text { of disease }\end{array}$ & $\begin{array}{l}\text { Undiagnosed cases } \\
n=64\end{array}$ & $\begin{array}{l}\text { Diagnosed cases } \\
n=33\end{array}$ & $\begin{array}{l}\text { Total } \\
n=97\end{array}$ \\
\hline Acute & $15(22 \%)$ & $6(18 \%)$ & $21(22 \%)$ \\
Acute/chronic & $8(12 \%)$ & $7(21 \%)$ & $15(15 \%)$ \\
Chronic & $41(66 \%)$ & $20(61 \%)$ & $61(63 \%)$ \\
\hline
\end{tabular}


Table 5 Incidence of clinical signs in the Wernicke-Korsakoff complex: literature review

\begin{tabular}{|c|c|c|c|c|c|}
\hline \multirow[t]{2}{*}{ Author } & \multicolumn{5}{|l|}{ Clinical signs } \\
\hline & $\begin{array}{l}\text { Number } \\
\text { of cases }\end{array}$ & $\begin{array}{l}\text { Classical } \\
\text { triad }\end{array}$ & Eye signs & Ataxia & Mental changes \\
\hline $\begin{array}{l}\text { Pathological studie } \\
\text { This study } \\
\text { Cravioto }^{4} \\
\text { Riggs et al }^{11} \\
\text { Grunnett et al }^{12} \\
\text { Campbell et al } \\
\text { Wallis et al }^{14} \\
\text { Barrie } \\
\text { Total }\end{array}$ & $\begin{array}{r}97 \\
28 \\
42 \\
24 \\
12 \\
4 \\
3 \\
210\end{array}$ & $\begin{array}{l}16 \\
4 \\
0 \\
0 \\
0 \\
0 \\
0 \\
20(10 \%)\end{array}$ & $\begin{array}{r}28 \\
9 \\
10 \\
6 \\
5 \\
0 \\
2 \\
60(29 \%)\end{array}$ & $\begin{array}{c}36 \\
5 \\
4 \\
3 \\
0 \\
\text { NA } \\
0 \\
48(23 \%)\end{array}$ & $\begin{array}{r}74 \\
26 \\
36 \\
18 \\
11 \\
4 \\
3 \\
172(82 \%)\end{array}$ \\
\hline $\begin{array}{l}\text { Clinical studies } \\
\text { Victor et } \mathrm{al}^{3} \\
\text { Groen }^{10} \\
\text { Total }\end{array}$ & $\begin{array}{c}163-232 \\
50 \\
213-282\end{array}$ & $\begin{array}{l}\text { NA } \\
\text { NA } \\
\text { NA }\end{array}$ & $\begin{array}{c}223 / 232 \\
40 \\
263(93 \%)\end{array}$ & $\begin{array}{l}163 / 188 \\
23 \\
186(78 \%)\end{array}$ & $\begin{array}{l}206 / 229 \\
44 \\
250(90 \%)\end{array}$ \\
\hline
\end{tabular}

NA = data not available.

were some cases with diseases such as septicaemia or massive haematemisis where it was irrelevant. However, these were in the minority and many patients had deteriorated and died suddenly without explanation (even considering the necropsy findings). Diagnosis and treatment may well have been effective in some of these cases and several of these patients have been written up elsewhere. ${ }^{67}$

Investigations of vitamin status were performed in only 12 cases and studies of thiamine status in only four of these. Two were normal and two were below normal. The most consistent abnormality was a low serum folate which was noted in 7 of 9 cases. Vitamin B1 2 levels were normal in 6 of 8 cases and pyridoxine in 4 of 4 instances.

A disturbing feature of the study was the fact that 10 of the acute or acute/chronic cases who died in hospital had received thiamine during their terminal admission. The dosages and routes of administration varied considerably but 7 of 10 cases had received daily thiamine (4 of 7 oral and 3 of 7 parenteral) for periods varying from two to 23 days. One patient had received intramuscular thiamine $100 \mathrm{mg} /$ day for 12 days prior to his death.

\section{Discussion}

With regard to the clinical diagnosis of the WernickeKorsakoff complex this study emphasises the importance of the application of less rigid diagnostic criteria than those noted by Wernicke in his original description of the disease ${ }^{2}$ and perpetuated by many medical textbooks. This latter fact is highlighted by statements in some of the textbooks which are commonly used by medical students. Harrison's "Principles of internal Medicine"8 states that "the clinical diagnosis of Wernicke's disease can hardly be made without evidence of an ocular disturbance".
Applied to this study, $71 \%$ of the cases would not be diagnosed. Similarly Cecil's "Textbook of Medicine" states that "horizontal nystagmus is almost always present". These statements are based largely on clinical studies of the Wernicke-Korsakoff complex such as that of Victor and his colleagues ${ }^{3}$ and Groen et $a^{10}$ as cited in table 5. Other retrospective pathological studies ${ }^{41-15}$ confirm our impressions that the clinical signs of ophthalmoplegia, nystagmus, ataxia and mental changes are by no means invariably present in cases of the Wernicke-Korsakoff complex. A summation of the clinical data from previously published pathological studies (table 5) indicates that only $10 \%$ of patients had the full clinical triad, $23 \%$ had ataxia, $29 \%$ had eye signs and $82 \%$ had mental changes. By contrast in clinical studies the majority of patients have the classical clinical triad, $70 \%$ had ataxia, $93 \%$ had eye signs, and $90 \%$ had mental changes.

With reference to ataxia, Cecil's "Textbook of Medicine" states that "it may be so slight that only special tests for cerebellar function betray its existence". 9 This comment perhaps goes part way to explaining the considerable discrepancies between the incidence of clinical signs in the clinical and pathological studies cited in table 5 . Significant clinical signs of the Wernicke-Korsakoff complex may well be missed unless clinicians have a high index of suspicion and take great care in the examination of "at risk" patients. Particular attention should be given to patients with a background history of alcoholism or malnutrition but other groups such as patients on prolonged intravenous feeding, ${ }^{6}$ starvation diets ${ }^{16}$ or patients presenting with unexplained confusion, obtundation or coma ${ }^{614}$ or hypothermia ${ }^{17}$ must also be considered as potential cases of the WernickeKorsakoff complex. Most cases are in adults but occasional childhood cases have been reported. ${ }^{18}$ Both 
Harper $^{1}$ and Lishmann ${ }^{19}$ have suggested the possibility that subclinical forms of the WernickeKorsakoff complex may exist, repeated attacks giving rise to the pathological entity of chronic Wernicke's encephalopathy. This hypothesis is supported by the apparent dichotomy between the incidence of clinical signs in the clinical and pathological studies of the Wernicke-Korsakoff complex (table 5). In fact, by extrapolating from the necropsy incidence figures, ${ }^{1}$ the number of patients dying in Perth each year with the Wernicke-Korsakoff complex should be approximately 200 whereas only about 30 new cases are diagnosed clinically each year in the major hospitals in Perth (an incidence of $0.04 \%$ of all admissions which is comparable with the incidence of $0.05 \%$ from the Massachusetts General Hospital ${ }^{20}$ ). Thus even allowing for a bias in selection of necropsy cases there appears to be a considerable number of cases of the Wernicke-Korsakoff complex which are not diagnosed clinically. However a prospective clinical and pathological (necropsy) study is necessary to determine if pathologically confirmed cases of chronic Wernicke's encephalopathy can be identified in patients who have been adequately examined clinically and have none of the recognised signs of the Wernicke-Korsakoff complex. As shown in this paper, the most common clinical sign in patients with the Wernicke-Korsakoff complex relates to abnormalities of higher mental functions and level of consciousness. These clinical signs are abnormal in a wide variety of central nervous system and systemic disorders and hence are relatively "soft" clinical signs compared to the eye signs and even ataxia. Thus as stated previously clinicians must maintain a high index of suspicion in order to make the diagnosis of the Wernicke-Korsakoff complex and if there is any doubt as to the diagnosis a large parenteral dose of thiamine should be given. The clinical response, in the case of thiamine deficiency, is usually dramatic enough to be virtually diagnostic.

The authors are grateful for the cooperation of the Forensic Department of the State Health Department. Miss Gail Della Torre prepared the manuscript and $\mathrm{Mr}$ Richard Timm assisted with the illustration.

\section{References}

${ }^{1}$ Harper CG. The incidence of Wernicke's encephalopathy in Australia-A neuropathological study of 131 cases. $J$
Neurol Neurosurg Psychiatry 1983;46:593-8.

${ }^{2}$ Wernicke C, ed. Die äkute hamorrhagische Polioencephalitis superior. In: Lehrbuch der Gehirnkrankheiten fär Ärzte und Studierende. Bd.II Kassel: Fisher, 1881:229.

${ }^{3}$ Victor M, Adams RD, Collins GH. The WernickeKorsakoff Syndrome. Contemporary Neurology Series. Oxford: Blackwell, 1971.

${ }^{4}$ Cravioto H, Korein J, Silberman J. Wernicke's encephalopathy. A clinical and pathological study of 28 autopsied cases. Arch Neurol 1961;4:510-9.

${ }^{5}$ Reuler JB, Girard DE, Cooney TG. Wernicke's encephalopathy. N Eng J Med 1985;312:1035-9.

${ }^{6}$ Harper CG. Sudden, unexpected death and Wernicke's encephalopathy. A complication of prolonged intravenous feeding. Aust NZ J Med 1980;10:230-5.

${ }^{7}$ Harper CG. Confusion, coma and death from a preventable disease. Med J Aust 1981;2:219-21.

${ }^{8}$ Victor M, Adams RD. Deficiency diseases of the nervous system. In: Petersdorf, Adams, Braunwald, Isselbacher, Martin and Wilson, eds. Harrison's Principles of Internal Medicine. 10th ed. New York: McGraw-Hill Book Co, 1983:2112-5.

${ }^{9}$ Plum F. Neurologic and behavioural disorders. In: Wyngaarden JB, Smith LH, Jr eds. Cecil Textbook of Medicine. 16th ed. Philadelphia: WB Saunders Co, 1982:2046-7.

${ }^{10}$ Groen RH, Hoff HCW. Wernicke's disease. A catamnestic study of 50 patients. Eur Neurol 1977;15:109-15.

${ }^{11}$ Riggs HE, Boles RS. Wernicke's Disease. QJ Stud Alcohol 1944; 5:361-70.

${ }^{12}$ Campbell ACP, Biggart JH. Wernicke's Encephalopathy: Its Alcoholic and Nonalcoholic Incidence. $J$ Pathol Bact 1930;48:245-62.

${ }^{13}$ Grunnet ML. Changing incidence, distribution and histopathology of Wernicke's polioencephalopathy. Neurology (Minneap) 1969;19:1135-9.

${ }^{14}$ Wallis WE, Willoughby E, Baker P. Coma in the Wernicke-Korsakoff syndrome. Lancet 1978;2:400-1.

${ }^{15}$ Barrie HJ. Wernicke's encephalopathy in surgical practice. Report of three cases. Lancet 1947;2:278-9.

${ }^{16}$ Dreneck EJ, Joven CB, Swendseid ME. Occurrence of acute Wernicke's encephalopathy during prolonged starvation for the treatment of obesity. $N$ Engl J Med 1966;274:937-9.

${ }^{17}$ Ackerman WJ. Stupor, bradycardia, hypotension and hypothermia. West J Med 1974;121:428-9.

${ }^{18}$ Meyers CC, Schochet SS, Jr, McCormick WF. Wernicke's encephalopathy in infancy. Development during parenteral nutrition. Acta Neuropathol (Berl) 1978;43:267-9.

${ }^{19}$ Lishman WA. Cerebral disorder in alcoholism: Syndromes of impairment. Brain 1981;104:1-20.

${ }^{20}$ Victor M, Laureno R. Neurologic complications of alcohol abuse: epidemiologic aspects. In: Schoenberg BS, ed. Advances in Neurology Vol 19. New York: Raven Press, 1978. 